\title{
AN EFFECT OF CASTRATION ON THE TESTOSTERONE-LH RELATIONSHIP IN MALE RATS
}

\author{
J. M. DAVIDSON, ERLA R. SMITH AND D. A. DAMASSA \\ Department of Physiology, Stanford University School of Medicine, \\ Stanford, California 94305, U.S.A.
}

(Received 6th March 1974)

\begin{abstract}
Summary. Following suppression of plasma LH titres in castrated male rats by various doses of testosterone propionate, a more rapid return to pretreatment levels was seen when a period of 8 (or 5) weeks intervened between castration and onset of treatment. This effect was not related to differential retention of testosterone in the circulation.
\end{abstract}

Altered sensitivity of certain target tissues to their trophic hormones is known to occur following prolonged removal of these hormones (Damassa \& Davidson, 1973). Can this concept be extended to the response of gonadotrophin to feedback suppression by androgen? This study was designed to compare the changes in plasma LH levels in rats held in (1) a 'maintenance' (M) condition, for which treatment commenced at the time of castration and (2) a 'restoration' (R) condition, for which treatment commenced several weeks later.

Adult male Long-Evans rats were castrated by a trans-scrotal approach under ether anaesthesia. Commencing either on the day of castration (M), or 8 weeks later (R), testosterone propionate (TP) in sesame oil or oil alone (controls) was injected subcutaneously each morning for 7 days. All animals were 120 days old at the onset of the injections, and there were five rats per group. Rapid blood sampling under ether anaesthesia began 4 to $6 \mathrm{hr}$ after the last injection (Day 0) and was repeated on the afternoons of Days 1, 5 and 7. Assays of LH were carried out on triplicate samples of plasma using the double antibody radioimmunoassay of Niswender, Midgley, Monroe \& Reichert (1968). All values were expressed in terms of the standard NIH-LHRP-1 (potency $=0.03 \times$ NIH-LH-S-1). Plasma testosterone was measured by radioimmunoassay using the method of Bartke, Steele, Musto \& Caldwell (1973) but omitting the chromatographic separation (Hillier, Brownsey \& Cameron, 1973).

Text-figures 1 and 2 show that the plasma LH values in the TP-treated groups were generally similar on Days 0 and 1 . Two-way analysis of variance on the Day-0 data showed significant effects $(P<0.01)$ due to dose $(F=17 \cdot 2$; d.f. 5 and 48$)$ and $M$ versus $\mathrm{R}(F=23.6$; d.f. 1 and 48$)$ with no significant interaction $(F=1.5$; d.f. 5 and $48 ; P>0.05)$. Values for control (and therefore treated) groups were higher in the $R$ condition because treatment started a longer time after castration. Analysis by $t$ tests showed that the lowest dose of TP which decreased plasma LH significantly on Day 0 when compared to the level in 
controls injected with oil was $25 \mu \mathrm{g} / 100 \mathrm{~g} /$ day $(P<0.05$ for $\mathrm{R}$ and $P<0.01$ for $M)$. Suppression to levels very similar to those found in intact controls (shamoperation) were obtained in both situations at the $100-\mu \mathrm{g}$ dose.

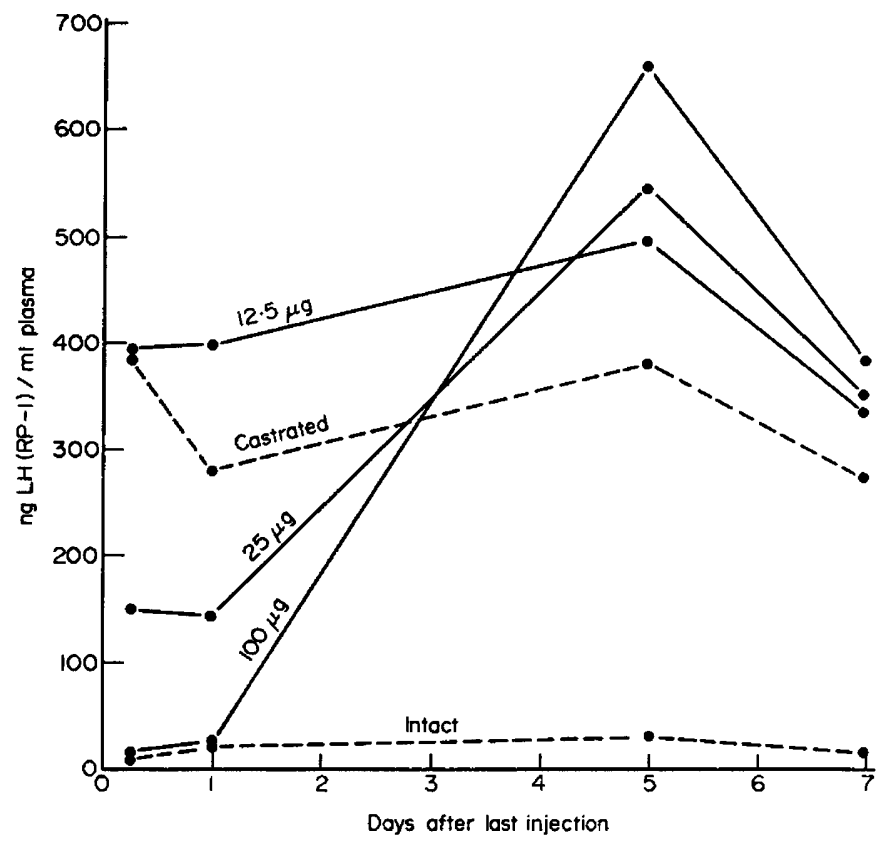

TEXT-FIG. 1. Experiment 1. The recovery of LH from feed-back suppression in 'restoration' groups of male rats treated with various doses of TP injected daily for 7 days starting 8 weeks after castration.

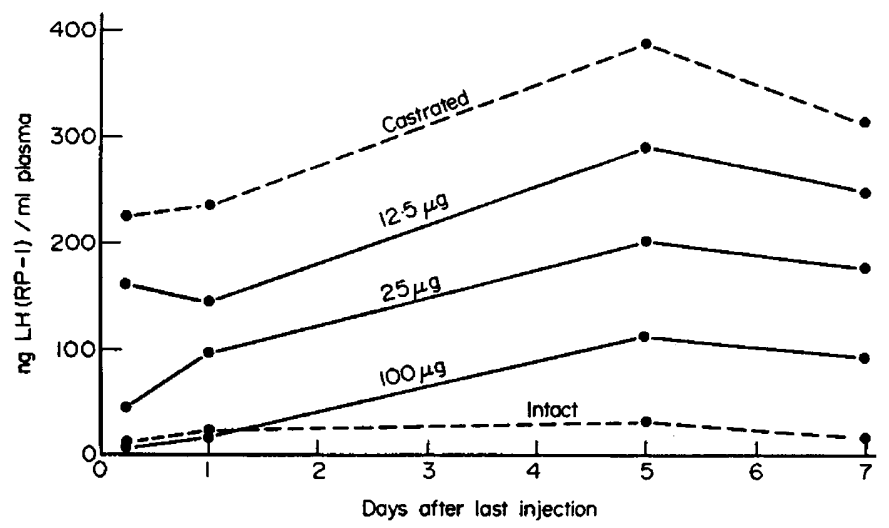

Text-Fic. 2. Experiment 1. The recovery of LH from feed-back suppression in 'maintenance' groups of male rats treated with various doses of TP injected daily for 7 days starting on the day of castration.

A striking divergence between the two conditions appeared, however, on subsequent days of sampling. The recovery of plasma LH from suppression was markedly slower in the $M$ than in the $R$ condition. Two-way analysis of variance on the Day-5 data showed a significant difference for $\mathbf{M}$ versus $R$ 
$(F=60.9$; d.f. 1 and $48 ; P<0.01)$, but not for dose $(F=0.06$; d.f. 5 and $48 ; P>$ $0.05)$. There was, however, a significant interaction $(F=6.4$; d.f. 5 and 48 ; $P<0.01)$. Inspection of the data shows that on Day 5 all the $\mathbf{M}$ groups still showed a (dose-dependent) suppression of plasma LH. The means of all $\mathbf{M}$ groups were lower, and of all $R$ groups were higher than those of their respective controls on that day.

Table 1. Plasma testosterone levels of male rats treated with testosterone propionate immediately after (maintenance) or 8 weeks after (restoration) castration

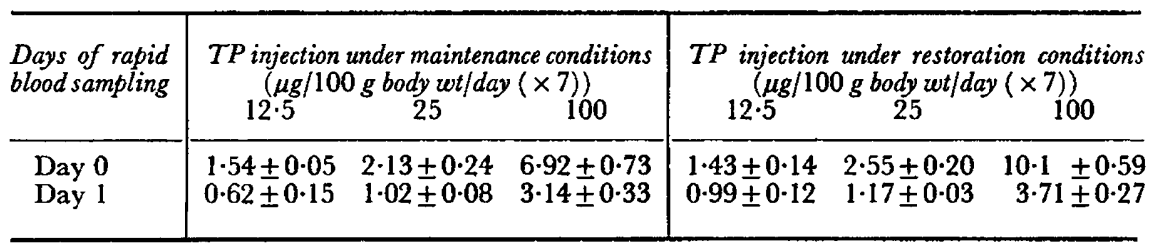

Plasma testosterone levels are expressed as mean values in $\mathrm{ng} / \mathrm{ml} \pm$ S.E. TP $=$ testosterone propionate.

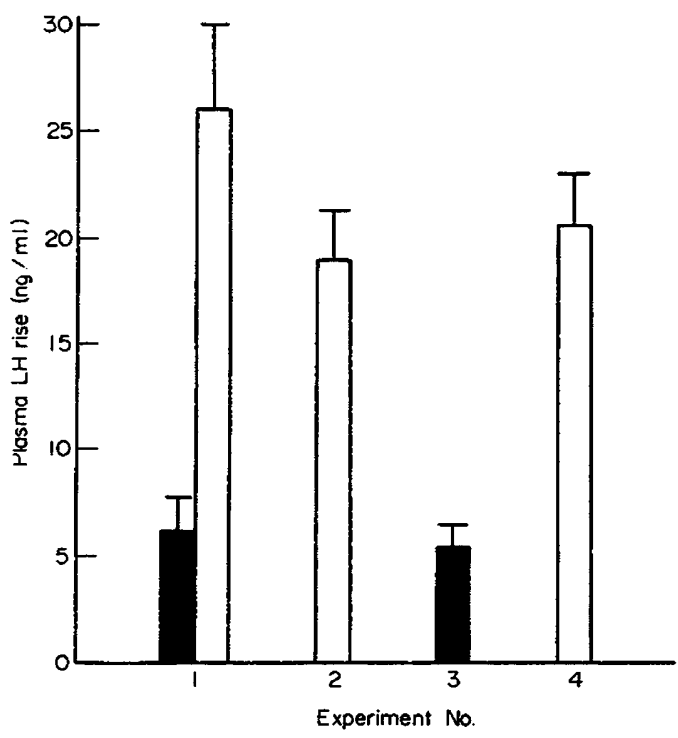

TExT-FIG. 3. Summary of LH recovery data from animals in all four experiments treated with $100 \mu \mathrm{g} \mathrm{TP} / 100 \mathrm{~g}$ body wt/day. The plasma $\mathrm{LH}$ rise was calculated by dividing each individual plasma LH value on Day 5 by that obtained on Day 1 in the same animal. Vertical bars represent the S.E.M. Open columns are values for rats in the 'restoration' groups; solid columns are values for rats in the 'maintenance' groups.

Plasma testosterone was determined for the TP-treated groups. The values on Days 0 and 1 are shown in Table 1; by Day 5, all animals had values below $0.36 \mathrm{ng} / \mathrm{ml}$ (non-detectable in the assay conditions used). There were no significant differences between testosterone levels in the $\mathbf{M}$ or $\mathbf{R}$ groups on any of the days, except that the group receiving $100 \mu \mathrm{g}$ showed a significantly higher value in the $R$ than in the $M$ condition, on Day $0(P<0.01)$. 
To confirm and extend these findings, three additional experiments were done. Experiments 2 and 4 repeated the R groups of Exp. 1 except that, in Exp. 2, 25 and $100 \mu$ g were the only doses and the rats were older than in Exp. 1, and, in Exp. 4, a shorter time lapse of 5 weeks following castration was used. Experiment 3 utilized the $\mathrm{M}$ schedule. In all three experiments, the 25- $\mu \mathrm{g}$ dose had suppressed plasma LH below control levels at the cessation of treatment. Text-figure 3 summarizes the critical data from all four experiments relevant to the recovery of plasma $\mathrm{LH}$ from suppression by $100 \mu \mathrm{g} \mathrm{TP}$, which was the only dose used which consistently suppressed LH to within the basal range. It clearly illustrates the rebound of plasma $\mathbf{L H}$ by Day 5 in the $R$ but not in the $M$ experiments.

These results provide information concerning the dose ranges necessary (1) significantly to reduce plasma LH in the castrated rat and (2) to restore normal circulating LH levels. The finding of major interest, however, was the striking difference in rates of recovery of plasma LH from feed-back suppression which resulted from a delay after castration. As shown by the testosterone assay, the results could not be explained by prolonged differential retention of testosterone in the circulation, due, for example, to slow release from the fat depôts. It appears, rather, that following prolonged absence of testosterone, the LHregulating mechanism assumes a greater reactivity which results in a faster rebound from feed-back suppression. Patients with Klinefelter's syndrome have also recently been shown to display a more rapid rebound of plasma LH from suppression by injection of TP than did normal controls (Capell, Paulsen, Derleth, Skoglund \& Plymate, 1973), but the suppression of LH by TP was also less than in normal individuals.

This study was supported by NIH grant HD 00778. Radioimmunoassay agents were kindly supplied by Dr G. D. Niswender, Dr L. E. Reichert, Dr B. V. Caldwell and Dr A. F. Parlow (NIAMD program). We are grateful to Dr A. Frankel and Mr E. Mock for help in establishing the testosterone assay.

\section{REFERENCES}

Bartke, A., Stezle, R. E., Musto, N. \& Caldwell, B. V. (1973) Fluctuations in plasma testosterone levels in adult male rats and mice. Endocrinology, 92, 1223.

Capell, P. T., Paulsen, G. A., Derleth, D., Skoglund, R. \& Plymate, S. (1973) The effect of shortterm testosterone administration on serum FSH, LH and testosterone levels: evidence for selective abnormality in LH control in patients with Klinefelter's syndrome. J. clin. Endocr. Metab. 37, 752.

Damassa, D. \& Davidson, J. M. (1973) Effects of ovariectomy and constant light on responsiveness to estrogen in the rat. Horm. \& Behav. 4, 269.

Hillier, S. G., Brownsey, B. G. \& Cameron, E. H. D. (1973) Some observations on the determination of testosterone in human plasma by radioimmunoassay using antisera raised against testosterone3-BSA and testosterone-11-alpha BSA. Steroids, 21, 735.

Niswender, G. D., Midgley, A. R., Monroe, S. E. \& Reichert, L. E. (1968) Radioimmunoassay for rat luteinizing hormone with anti-ovine LH serum and ovine LH. Proc. Soc. exp. Biol. Med. 128, 807. 